\title{
Self-medication practices with antibiotics among nursing students: A cross- sectional descriptive survey at tertiary care teaching hospital in Uttarakhand
}

\author{
Kshitiza Sharma $^{a}$, Suresh K. Sharma ${ }^{a}$, Rakhi Gaur ${ }^{\mathrm{a}, *}$, Shiv K. Mudgal ${ }^{\mathrm{a}}$, Pratima Gupta ${ }^{\mathrm{b}}$, \\ Maneesh Sharma ${ }^{\mathrm{a}}$ \\ ${ }^{a}$ College of Nursing, AIIMS, Rishikesh, Uttarakhand, India \\ ${ }^{\mathrm{b}}$ Department of Microbiology, AIIMS, Rishikesh, Uttarakhand, India
}

\section{A R T I C L E I N F O}

\section{Keywords:}

Self-medication

Antibiotic

Undergraduate nursing students

\begin{abstract}
A B S T R A C T
Background: Misuse and overuse of antimicrobials is one of the world's most pressing public health problems. Nurses are important members of healthcare team and thus it is essential to know behaviour of antibiotics use among budding nurses.

Aim \& objective: To assess prevalence and practices of self-medication with antibiotic among undergraduate nursing students.

Methods and material: This cross-sectional descriptive study was conducted on 216 randomly selected undergraduate nursing students studying at a tertiary care teaching hospital in Uttarakhand. Data was collected using a valid and reliable questionnaire for self-medication practices with antibiotics and were analysed by using descriptive statistics.

Results: Prevalence of self-medication with antibiotics was 78.7\% and among them 53.5\% practiced it for $2-3$ times in past one year. Azithromycin (37.5\%) and Amoxicillin (30.1\%) were commonly used antibiotics, primarily for the treatment of sore throat $(30.6 \%)$ and fever $(27.1 \%)$. The main reasons for self-medication were adequate knowledge of antibiotics use (39.4\%), and to save time $(30.6 \%)$ \&cost $(13.5 \%)$. The main source of obtaining antibiotics was hospital pharmacy (66\%) with verbal advice from nurses/paramedical staff (32.3\%) and senior undergraduate nursing students (23.7\%). Surprisingly, 68.3\% participants suddenly stopped the antibiotic use and $52.7 \%$ of them changed over the drugs during treatment.

Conclusions: High prevalence of self-medication practices with antibiotics among budding nurses is a serious issue; which necessitate educating them with risks and harms of inappropriate use of antimicrobials. Furthermore, sensitizing the pharmacists for not advising and selling antibiotics without medical prescription.
\end{abstract}

\section{Introduction}

Self-medication is the term used for consumption of drugs without medical prescription for self-diagnosed symptoms. ${ }^{1}$ It includes getting drugs from over the counter, from friends or taking leftover drugs and use them without valid prescription. ${ }^{2}$

Self-medication with antibiotics became a very common practice across the globe and is very prevalent in developing countries like India ${ }^{2,3}$ and in some developed countries like Greece ${ }^{4}$ as well. Practice of self-medication with antibiotics are more prevalent in developing countries because of insufficient health care facilities, easy accessibility of over-the-counter medicine, lack of strict government rules and high prevalence of infectious diseases. ${ }^{5}$ Practice of self-medication with antibiotics differ from population to population and it is associated with various factors like age, gender, education, having any disease, accessibility of medicines etc. ${ }^{6}$

Though, self-medication with antibiotics reported few advantages like reducing the severity of symptoms, duration of disease but it's disadvantages are even more such as resistant microorganisms, treatment failures, drug toxicity, increase in the cost of treatment, prolonged hospitalization periods and increase in morbidity. ${ }^{7,8}$

Thus, excessive and inappropriate use of antibiotics are leading to "Antibiotic Resistance Era", and if this indiscriminate and improper use of antibiotics will not be checked then, the day is not so far we will land up facing "Drug Resistant Pandemics. ${ }^{8}$

Practice of self-medication with antibiotics has been termed, as ' $a$

\footnotetext{
${ }^{*}$ Corresponding author.

E-mail addresses: kshitizasharma03@gmail.com (K. Sharma), sk.aiims17@gmail.com (S.K. Sharma), rakhigaur1308@gmail.com (R. Gaur), Peehupari05@gmail.com (S.K. Mudgal),drpratima68@gmail.com (P. Gupta), manishsharma740@gmail.com (M. Sharma).
} 
silent epidemic' and one of the study also mentioned this as major problem among undergraduate students. ${ }^{9}$ Self-medication with antibiotics among undergraduate nursing students is more common ${ }^{9}$ and a special attention should be given to address this issue because they are future health care providers and tomorrow's future lies in the hands of today's generation. ${ }^{10}$ Therefore, it is needed to inculcate safe practices of medication among undergraduate nursing students and sensitize them through proper education on deleterious consequences of self-medication practices.

Hence, this study was carried out to find out the practice of selfmedication with antibiotics among undergraduate nursing students at tertiary care teaching public hospital in Uttarakhand to get insight into this issues among undergraduate student nurses, who are considered as the future manpower of the healthcare in the country. Furthermore, nurses spend majority of their time with the people either at community or hospital and their knowledge, attitude and practices of self-mediation can largely impact the prevention of inappropriate use of antibiotics among common man of the country.

\section{Objective}

The purpose of the study was to assess the prevalence and practice of self-medication with antibiotic among undergraduate nursing students.

\section{Methodology}

\subsection{Study design}

This was a single-centric, cross-sectional descriptive study.

\subsection{Study setting \& duration}

This study was carried out at All India Institute of Medical Sciences, Rishikesh, Uttarakhand, India. Data were collected during Feb. 2nd to March 31st’ 2019.

\subsection{Study population}

Study population comprised of B.Sc. (Hons.) undergraduate nursing students studying at All India Institute of Medical Sciences, Rishikesh.

\subsection{Sample size \& sampling}

Sample size was calculated by using formula, $=\mathrm{N} / 1+\mathrm{Ne}^{2}$ and minimum estimated sample size was 216 based on $\mathrm{N}=$ Population size (316), absolute error of margin $5 \%$, confidence interval as $95 \%$ and $25 \%$ as non-response rate. ${ }^{11}$ Thus, we included 216 participants in this study. A sampling frame was prepared including all four batches of B.Sc. (Hons) Nursing and sample was chosen by using simple random sampling technique. Computer generated random table was preferred to employ simple random sampling technique to avoid any chance of error.

\subsection{Inclusion \& exclusion criteria}

Total 269 undergraduate nursing students who were willing to participate and had given consent for the study were included in the study. Forty seven undergraduate nursing students who participated in reliability testing (twenty participants) and pilot study (twenty participants), known allergic to antibiotics and take only alternative therapies (seven participants) were excluded from the study.

\subsection{Data collection}

Data were collected after approval received from competent authority. Data were collected using a modified standardized semistructured questionnaire for self-medication with antibiotics. ${ }^{12}$ The final tool included two sections i.e. Section-A: Self-structured sociodemographic characteristics data sheet that included age, year of study, and residential details of participants. Section-B: Questionnaire for selfmedication practices with antibiotics, which consisted 14 questions related to frequency, type, sources of obtaining antibiotics, chief complaints, factors considering while selecting antibiotic and reasons for switching another antibiotics. There are two different types of questions (yes/no type and multiple choice type) in the questionnaire. There were no marks for the answers. The data collection instrument was validated by seven different experts from different speciality areas like infectious diseases, internal medicine, epidemiology and nursing. The test-retest reliability was measured and for that the same questionnaire were sent to twenty participants after two weeks and they were asked to respond for the same. Then, by using correlation coefficient, the test-retest reliability was determined and tool was found to be reliable $(r=0.87)$. The participants who were involved in reliability detection were excluded from the main study.

\subsection{Data and statistical analysis}

There was $100 \%$ response rate as undergraduate nursing students were instructed not to leave any question unanswered. The average time taken to administer the tool was $30 \mathrm{~min}$ and data were analysed by using descriptive statistics with SPSS version 16.0 as per the study objectives. Frequency and percentage were calculated for the selfmedication practices among undergraduate nursing students.

\subsection{Ethical justification}

Ethical clearance was obtained from the Institutional Ethics Committee of AIIMS, Rishikesh [IECNo.08/IEC/STS/2019]. Informed consent was also obtained from each participant who were included in the study. Data were collected after receiving formal permission from the competent authority.

\section{Results}

\subsection{Participants characteristics}

There were all female participants $(100 \%)$ as college selected for study did not enrol any male candidates in B.Sc. (Hons) Nursing programme. More than half of the participants (7 7\%) were within the age group of 20-22 years with $21.21 \pm 1.61$ mean age. Study reported that participants from first, second, third and fourth year were 59 (27.3\%), 56(25.9\%), $54(25.0 \%)$, and $47(21.8 \%)$ respectively. 56\% were residents of semi-urban areas.

\subsection{Prevalence of self-medication with antibiotics}

Data shows that prevalence of self-medication with antibiotic was $78.7 \%$ and significant number of them has consumed multiple times in last one year ( $>3$ times-37.2\%; $2-3$ times-53.5\% and $\leq 2$ times$19.3 \%$ ). Out of 216 undergraduate nursing students from all the batches, 170 participants were involved in self-medication with antibiotics practices. However, there is decreasing trends of self-medication practices with antibiotics in undergraduate nursing students from first to fourth year i.e. highest among I year (88.6\%) followed by II year (75\%), III year $(74.4 \%)$ and IV year $(72.7 \%)$ respectively (Fig. 1).

\subsection{Types of antibiotics used and sources of obtaining antibiotics}

Azithromycin and amoxicillin were the two commonly used antibiotics by the undergraduate nursing students of all batches. Azithromycin was used by $59.7 \%$ in first year followed by $51.4 \%$ in 




Fig. 1. Prevalence of self-medication with antibiotics among undergraduate nursing students $\mathrm{N}=170$.

Table 1

Type of antibiotics commonly self-administered by undergraduate nursing students $\mathrm{N}=170$.

\begin{tabular}{|c|c|c|c|c|c|}
\hline \multirow[t]{2}{*}{ Type of antibiotic } & \multicolumn{5}{|l|}{ Class year } \\
\hline & First year f (\%) & Second year f (\%) & Third year f (\%) & Fourth year f (\%) & Total f (\%) \\
\hline Azithromycin & 27 (51.9) & $21(48.8)$ & $15(37.5)$ & $18(51.4)$ & $81(37.5)$ \\
\hline Amoxicillin & $14(26.9)$ & $15(34.9)$ & $23(57.5)$ & $13(37.1)$ & $65(30.1)$ \\
\hline Others* & $11(21.2)$ & $07(16.3)$ & $02(6.1)$ & $04(11.4)$ & $24(11.1)$ \\
\hline
\end{tabular}

Others* include ofloxacin and ciprofloxacin.

fourth year, $37.5 \%$ in third year and $33.3 \%$ in second year. On the other hand, amoxicillin was used more i.e., $57.5 \%$ in third year and least i.e., $22.6 \%$ in first year. There were other drugs like ofloxacin and ciprofloxacin, which were used, but in minimum percentage. (Table 1).

The sources from where the undergraduate nursing students obtained antibiotics were explored and surprisingly $66 \%$ of them obtained antibiotics from hospital pharmacy without any legal prescription of registered medical practitioner; while $28 \%$ of them used left over medicines and only very few (6\%) took it from friends, seniors and nurses. (Fig. 2).

\subsection{Main reasons and complaints for practicing self-medication with antibiotics}

Table 2(a) shows that the reasons for self-medication with antibiotics were due to participants' self-thinking as they have appropriate knowledge regarding antibiotics 67 (39.4\%), while others did it for saving time 52(30.6\%), $28(16.5 \%)$ for considering illness as minor aliment and only $23(13.5 \%)$ to save cost. Self-medication with antibiotics was primarily done for the complaints of sore throat $52(30.6 \%)$, fever 46 (27.1\%), common cold and cough 31 (18.2\%), diarrhoea 21 (12.4\%), skin wounds $08(4.7 \%)$, UTI $06(3.5 \%)$, pain $04(2.4 \%)$, and

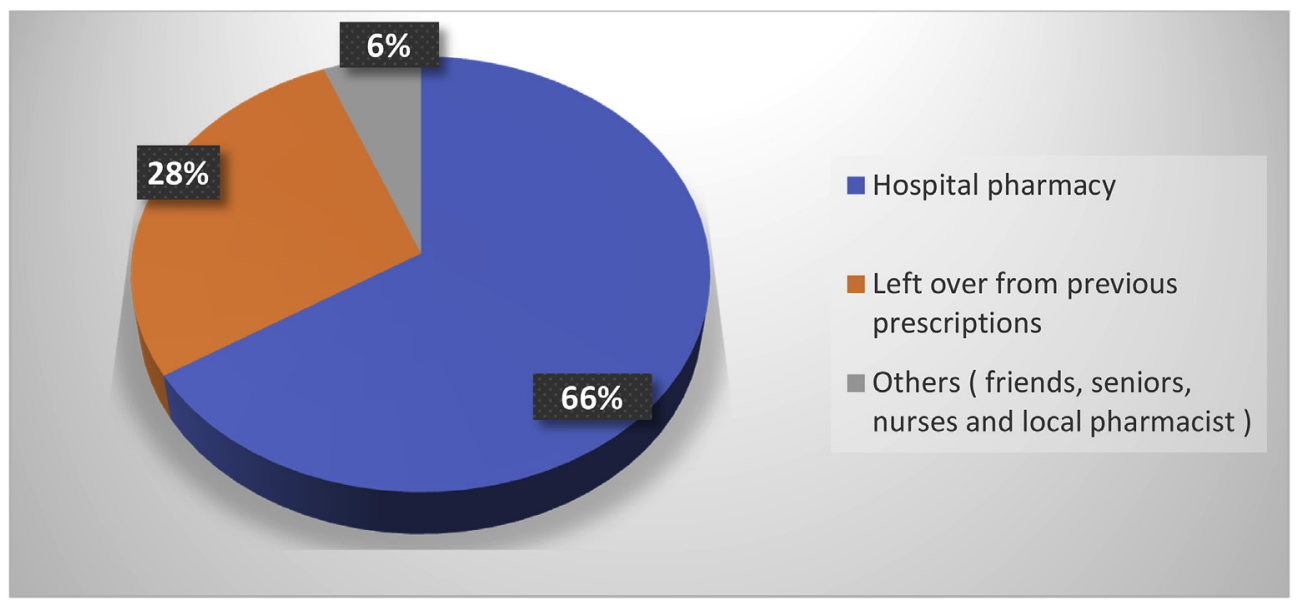

Fig. 2. Sources of obtaining antibiotics. 
Table 2

(a) and 2 (b): Main reasons and complaints for practicing self-medication with antibiotics among undergraduate nursing students $\mathrm{N}=170$.

\begin{tabular}{lc}
\hline 2 (a) Reasons for self-medication with antibiotics & $\mathrm{f}(\%)$ \\
\hline Knowledge regarding antibiotics & $67(39.4)$ \\
Time saving & $52(30.6)$ \\
Cost saving & $23(13.5)$ \\
Minor illness & $28(16.5)$ \\
2(b) Complaints for which self medication with antibiotics was preffered \\
Sore throat & $52(30.6)$ \\
Fever & $46(27.1)$ \\
Cold and cough & $31(18.2)$ \\
Diarrhoea & $21(12.4)$ \\
Skin wounds & $08(04.7)$ \\
UTI & $06(03.5)$ \\
Pain & $04(02.4)$ \\
Vomiting & $02(01.2)$ \\
\hline
\end{tabular}

vomiting $02(1.2 \%)$ Table $2(\mathrm{~b})$

\subsection{Advice for selection and factors considered to select the antibiotics}

It was reported that selection of antibiotic was based on advise of pharmacists, nurses and other paramedical staffs (32.3\%), friends or seniors (23.7\%), own experience (18.3\%), previous prescription (16.5\%) and family members $(9.2 \%)$. The main factors considered by participants while selecting antibiotic was brand (32.3\%), indications for use (31.1\%), price (23.1\%) and types (13.5\%) of antibiotic(Table 3 ).

\subsection{Reasons for switching and stopping antibiotic during the course}

Findings of the study revealed that just more than half $(52.7 \%)$ of the participants switched on to another antibiotic and the reasons reported by the participants were their former antibiotic did not work for $57.8 \%$, former antibiotic ran out for $19.6 \%$, later one was cheaper for $12.9 \%$ and due to side effects for $9.7 \%$.

The majority of participants $(68.3 \%)$ reported that they stopped their medication when symptoms disappeared, $17.4 \%$ stopped it after antibiotic ran out, only $14.3 \%$ stopped medications after completion of course. Surprisingly, $13.1 \%$ of participants have taken same antibiotics with different brand during the same course of treatment(Table 4).

\section{Discussion}

Self-medication practices with antibiotic is a major global issue. ${ }^{7}$ Practice of self-medication with antibiotic or inappropriate use of antibiotics may predispose the users to develop multitude of associated health hazards such as increased resistance to microbes, hide the symptoms of underling problems and adverse reactions. ${ }^{13}$

The presence of many multi-drug resistance microbes raised a serious issue about the antibiotic resistance around the globe. ${ }^{14}$ WHO has warned that the minor infections and injuries that were previously

Table 3

Advise for selection and factors considered when selecting antibiotics $\mathrm{N}=170$.

\begin{tabular}{lc}
\hline Advise for selection of antibiotics & $\mathrm{f}(\%)$ \\
\hline Pharmacists, nurses and other paramedical staff & $55(32.3)$ \\
Friends or seniors & $40(23.7)$ \\
Own experience & $31(18.3)$ \\
Previous prescription & $28(16.5)$ \\
Family members & $16(09.2)$ \\
Factors considered when selecting antibiotics & \\
Brand of antibiotic & $55(32.3)$ \\
Indications for use of antibiotic & $53(31.1)$ \\
Price of antibiotic & $39(23.1)$ \\
Types of antibiotic & $23(13.5)$ \\
\end{tabular}

Table 4

Reasons for switching and stopping antibiotic during the course $\mathrm{N}=170$.

\begin{tabular}{ll}
\hline Reasons for switching to another antibiotic & $\mathrm{f}(\%)$ \\
\hline Former antibiotic did not work & $98(57.8)$ \\
Former antibiotic ran out & $33(19.6)$ \\
Later one was cheaper & $22(12.9)$ \\
Own experience & $17(09.7)$ \\
Reasons for stopping of antibiotic & $116(68.3)$ \\
When symptoms disappeared & $30(17.4)$ \\
When antibiotic ran out & $24(14.3)$ \\
After completion of course & \\
\hline
\end{tabular}

manageable, now become a challenge for the whole world and campaign again misuse use of antibiotics have been declared. ${ }^{15}$ WHO has also recommended to organize World Antibiotic Awareness Week (WAAW) in November of every year with an aim to increase the global awareness of antibiotic resistance and encourage best practices among the general public, health workers and policy makers in order to further avoid the emergence and spread of antibiotic resistance. ${ }^{16}$ Because of irrational antibiotic use may lead to resist microbes and it may be responsible for prolonged hospital stay, frequent hospital visits, extended period of illness, use of costlier drugs and even death. ${ }^{14}$

The results of our study revealed that practice of self-medication with antibiotics was very common among undergraduate nursing students with a calculated prevalence of $78.7 \%$. The results of our study were highly comparable to other studies which have shown estimated range varies from $36 \%$ to $76.8 \%$ among medical, dental and nursing participants. ${ }^{17,18}$ The results of other studies conducted by Bala $R$ et al. ${ }^{17}$ and Biswas $\mathrm{S}$ et al. ${ }^{8}$ were also in line with the results of our study, which revealed that higher prevalence on self-medication were 87.0\%and $92.7 \%$ among undergraduate nursing students of professional courses and undergraduate health care nursing students respectively. However, one cross sectional study carried out at Institute of Nursing, Dow University of Health Sciences Karachi, Pakistan reported less prevalence $(52.7 \%)$ of self-medication with antibiotics among undergraduate nursing students. ${ }^{19}$ Results of various studies indicated that the prevalence of self-medication with antibiotics are very high among budding health care professionals particularly among undergraduate nursing students is an alarming situation. ${ }^{17-19}$ Nurses are the major healthcare manpower of the country and furthermore, nurses spend more time with healthcare seekers either at community or hospital and their knowledge, attitude and practices of self-mediation can largely impact the prevention of inappropriate use of antibiotics among common man of the country. Therefore, it is essential to incorporate specific topics regarding self-medication and its harmful effect in their nursing curriculum. In addition, focused educational programs can be conducted to support governmental actions to sensitize about the risks associated with the consumption of antibiotic without medical prescription. In our study, there were only female participants included and all of them belonged to the same educational course. Therefore, in this study the use of antibiotic could not be interpreted on the basis of gender and educational qualification.

Fever, sore throat, cold and cough were reported as the most common symptoms that led to self-medication with antibiotic in some studies. ${ }^{8,20}$ Similarly, in our study found that self-medication practices with antibiotics were mainly done for the treatment of sore throat, fever, cold and cough, gastrointestinal tract disorders, skin injuries, pain and urinary tract infection. However, there were studies that revealed gastrointestinal tract symptoms as common illness for which antibiotics were used. ${ }^{21,22}$ The practice of self-medication was very common because participants had self-thinking that they have adequate knowledge about the use of antibiotic, easy accessibility of drugs, mild nature of illness, and to save time and cost of consultation. The findings of our study are consistent with other studies, which have shown that the knowledge about antibiotic, mild nature of disease and to avoid 
doctor fee were the reasons that prevented them to seek legal consultation. ${ }^{21-23}$ Furthermore, in our study significant number of these undergraduate nursing students were repeated misusers of the antibiotics; which could be seriously dangerous for them. Therefore, they must be sensitized for righteous use of antibiotics after the consultation and prescription of a registered medical practitioner.

Biswas et al. $^{8}$ conducted a study among undergraduate nursing students showed that the most commonly used antibiotic were metronidazole, azithromycin and norfloxacin. In our study, azithromycin being the most common type of antibiotic used by undergraduate nursing students for self-medication for the treatment of sore throat, fever, cold and cough followed by amoxicillin, ofloxacin and ciprofloxacin and the possible reason could be that azithromycin is used for the treatment of bacterial infection. However, this drug does not work for cold, flu or other viral infection of upper respiratory tract and may mask or delay the symptoms of syphilis. Amoxicillin is a first line drug and used for urinary tract infection, pneumonia, infection of ear, nose throat or skin. Therefore, irrational use of antibiotic may lead to drug resistance, mistreatment, adverse drug interactions and severe side effect.

Various studies found that the most common source to get the antibiotics is from hospital pharmacy, leftover medicines stock, friends and relatives and drug stores. ${ }^{8,20-22}$ Results of our study also indicated that the most common source of antibiotics for self-medication is hospital pharmacy, leftover previous prescription, family and friends. Pharmacy personnel usually do not have an appropriate and up-to-date knowledge about significant use of antibiotic in specific disease condition. However, pharmacists are most common source of information and for obtaining antibiotic. Therefore, pharmacy personnel could play a crucial part in providing information about rational for use of antibiotic and stopping the sales of antibiotic as over the counter drug or without legal prescription.

In our study, majority of participants suddenly stopped the antibiotics when symptoms disappeared and more than half of them switched over to another antibiotic during the course. The studies regarding inappropriate use of antibiotics conducted on medical, dental and pharmacy undergraduate nursing students also revealed that sudden stop of an antibiotic course and switching over to same antibiotic course have been reported as $7.2 \%-77.6 \%$ and $12.79 \%$ respectively by many studies. ${ }^{20,23,24}$ This type of misuse of antibiotic can be potential cause for development of antibiotic resistance and limiting other option of antibiotic in future. This could further increase the financial burden on health care; which could be disastrous for a country like India where $70 \%$ healthcare expenditure are met by out of pocket expenditure by the individual and the highest percentage of out of pocket health expenditure is made towards purchase of medicines. ${ }^{25}$

\section{Conclusion}

This study has concluded that prevalence of self-medication with antibiotics is a common practice among undergraduate nursing students predominantly among first years. Majority of them suddenly stopped the antibiotics on relief of symptoms and more than half of them changed over the drugs during course of treatment; such inappropriate self-use of antibiotic may be detrimental. Adequate knowledge about rational use of antibiotics was major contributing factor in addition to convenience and cost saving. Educational activities focusing on prevention of inappropriate use of antibiotics and their harmful effects are very much needed. Furthermore, it is utmost important to encourage the pharmacist so that they stop giving advices and sales of antibiotic without legal prescription. Laws should be enacted in over the counter sale of antibiotics in India to prevent the country from becoming "antibiotic resistant".

\section{Limitations of the study}

1. It is a single centre study in one part of north India and hence findings of the study may not be generalized to the country.

2. Data regarding self-medication with antibiotics in last one year was self-reported by the participants. Therefore, there may be chances of recall bias.

\section{Source of funding}

No funding received for this study.

\section{Declaration of competing interest}

Authors do not have any conflict of interest.

\section{References}

1. Sah AK, Jha RK, Shah D. Self-medication with antibiotics among undergraduate nursingundergraduate nursing studentsss of Nepal. Int $J$ Pharma Sci Res. 2016;7(11):427-430. [Internet]. 2019 [cited 11 May 2019]. Available from:. http:// www.ijpsr.info/docs/IJPSR16-07-11-001.pdf.

2. Okeke I, Aboderin O, Byarugaba D, Ojo K, Opintan J. Growing Problem of MultidrugResistant Enteric Pathogens in Africa. . [Internet]. 2019 [cited 11 May 2019]. Available from:. https://www.ncbi.nlm.nih.gov/pmc/articles/PMC3375797/.

3. Ojo KK, Sapkota AR, Ojo TB, Pottinger PS. AASCIT - J - All Issues. . [Internet]. Aascit.org. 2019 [cited 11 May 2019]. Available from. http://www.aascit.org/ journal/archive2? journalId = 893\&paperId $=1859$.

4. Skliros E, Merkouris P, Papazafiropoulou A, et al. Self-medication with Antibiotics in Rural Population in Greece: A Cross-Sectional Multicenter Study. . [Internet]. 2019 [cited 11 May 2019]. Available from:. https://www.ncbi.nlm.nih.gov/pubmed/ 20691111.

5. Ebert SC. Factors Contributing to Excessive Antimicrobial Prescribing. 2019; 2019 PubMed - NCBI [Internet]. Ncbi.nlm.nih.gov. https://www.ncbi.nlm.nih.gov/ pubmed/17896905.

6. National Journal of Physiology P. National Journal of Physiology. . Pharmacy and Pharmacology [Internet]. Njppp.com. 2019 [cited 11 May 2019]. Available from: https://www.njppp.com/?mno $=30403$.

7. Nathwani D. Antibiotic Prescribingare There Lessons for Physicians? 2019; 2019 [cited 11 May 2019].

8. Biswas S, Ghosh A, Mondal K, Haldar M, Biswas S. . [Internet]. Pdfs.semanticscholar.org. 2019 [cited 11 May 2019]. Available from:. http://pdfs. semanticscholar.org/b67a/839b970cfdb525097f1534801e85485fa10f.pdf.

9. Franco JA, Pecci C. Studies in Patients of Clinical Practice and Mental Health. Selfmedication, the new silence epidemic https://www.ncbi.nlm.nih.gov/pubmed/ 18273419.

10. Mudgal SK. Assess learning needs of undergraduate nursingundergraduate nursing studentsss and effectiveness of workshop on knowledge regarding extended and expanded role of nurses. Int J Nurs Educ. 2018;10(3):109-113. [Internet] [cited 11 May 2018]. Available from: https://scholar.google.com/citations?user=ZLfcZEAAAAJ\&hl $=$ en.

11. Sharma SK, Mudgal SK, Thakur K, Gaur R. How to calculate sample size for observational and experimental nursing research studies? Natl J Physiol Pharm Pharmacol. 2020;10(Online First) https://doi.org/10.5455/njppp.2020.10. 0930717102019.

12. Questionnaire Unknown, For self-medication with antibiotics: file S1 PLOS. [cited 11 May 2019]. Available from:https://journals.plos.org/plosone/article/file?type= supplementary\&id = info:doi/10.1371/journal.pone.0041314.s002.

13. Nepal G, Bhatta S. Self-medication with antibiotics in WHO southeast asian region: a systematic review. Cureus. 2018 Apr;10(4):e2428.

14. Spellberg B, Guidos R, Gilbert D, et al. The epidemic of antibiotic resistant infections: a call to action for the medical community from the Infectious Diseases Society of America. Clin Infect Dis. 2008;46:155-164.

15. Nair M, Tripathi S, Mazumdar S, et al. Knowledge, attitudes, and practices related to antibiotic use in Paschim Bardhaman District: a survey of healthcare providers in West Bengal, India. J PLoS One. 2019;14(5). [Internet]. [cited 13 June 2019]. Available from: https://www.ncbi.nlm.nih.gov/pubmed/31150515.

16. WHO. World antibiotics awareness week. Available: https://www.who.int/newsroom/events/detail/2019/11/18/default-calendar/world-antibiotic-awarenessweek-2019/retrieved7/11/2019; 2019.

17. Bala R, Singh H, Kaur K, Girish P, Kohli K. Knowledge and attitude towards antimicrobial self-medication usage: a cross sectional study among medical and undergraduate nursingundergraduate nursing studentsss. Int J Basic Clin Pharmacol. 2013;2:428-432. [Internet]. [cited 3 June 2019]. Available from:https://www.ijbcp. com/index.php/ijbcp/article/view/1294.

18. Emmanuel A, Daniel G, Achema G, Afoi B, OnyejekweG Gimba SM. Self-medication practice among undergraduate undergraduate nursingundergraduate nursing studentsss of the university of Jos, Nigeria. Niger J Pharm Sci. 2011;10(2):23-26. [Internet]. [cited 3 June 2019]. Available from: https://pdfs.semanticscholar.org/ 6e09/389686ac0ecc81c18bb9e4add071bc05c288.pdf. 
19. Ali AS, Ahmed J, Ali AS, et al. Practices of self-medication with antibiotics among undergraduate nursingundergraduate nursing studentsss. J Pakistan Med Assoc. 2016 Feb;66(2):235-237. [Internet]. [cited 3 June 2019]. Available from:. https://www. ncbi.nlm.nih.gov/pubmed/26819180.

20. Shubha R, Savkar MK, Manjunath GN. Self-medication pattern among dentists with antibiotics. J Evol Med Dent Sci. 2013;2:9037-9041.

21. Biswas M, Roy MN, Manik MI, et al. Self-medicated antibiotics in Bangladesh: a cross-sectional health survey conducted in the Rajshahi City. BMC Publ Health. 2014:14:847-850.

22. Nair A, Doibale MK, Kulkarni SK, et al. Pattern of selfmedication with antibiotics among undergraduate medicalundergraduate nursing studentss of a government medical college. Int J Prev Publ Health Sci. 2015;1:9-13.

23. Seam MO, Bhatta R, Saha BL, et al. Assessing the perceptions and practice of selfmedication among Bangladeshi undergraduate pharmacyundergraduate nursing studentss. Pharmacy. 2018;6(1):6-10.

24. Pant N, Sagtani RA, Pradhan M, et al. Self-medication with antibiotics among dentalundergraduate nursing studentss of Kathmandu - prevalence and practice. Nepal Med Coll J. 2015;17:47-53.

25. Rao N. Who Is Paying for India's Healthcare. The Wire, 14th April. 2018; 2018 Available: https://thewire.in/health/who-is-paying-for-indias-healthcare/ retrieved7.8.2019. 